\title{
The lipoprotein lipase activator, N0-1886, suppresses fat accumulation and insulin resistance in rats fed a high-fat diet
}

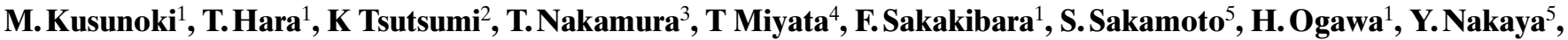 \\ L.H.Storlien ${ }^{6}$ \\ ${ }^{1}$ The First Department of Internal Medicine, Aichi Medical University, Aichi, Japan \\ ${ }^{2}$ The Nutrition Research Institute, Otsuka Pharmaceutical Factory, Tokushima, Japan \\ ${ }^{3}$ Laboratory of Biomedical Control, Research Institute for Electronic Science, Hokkaido University, Sapporo, Japan \\ ${ }^{4}$ Division of Vascular Surgery, Department of Surgery, Faculty of Medicine, The University of Tokyo, Tokyo, Japan \\ ${ }^{5}$ Department of Nutrition, School of Medicine, Tokushima University, Tokushima, Japan \\ ${ }^{6}$ Metabolic Research Centre, Dept. Biomedical Science, University of Wollongong, Australia
}

\section{Abstract}

Aims/hypothesis. Fat balance is critical in the aetiology of obesity and related diseases. Lipoprotein lipase is of major importance in lipid metabolism. The aim of this study was to investigate the long-term effects of the lipoprotein lipase activator, NO-1886, on substrate utilisation, adiposity and insulin action in rats fed a high-fat diet.

Methods. Male, Sprague-Dawley rats were fed for 10 weeks on a chow diet or a high-fat diet with, or without, NO-1886 $\left(50 \mathrm{mg} \cdot \mathrm{kg}^{-1} \cdot \mathrm{day}^{-1}\right)$. Weight gain, fat accumulation and both hormone-sensitive and lipoprotein, lipase activities were measured. Insulin action was assessed by the euglycaemic hyperinsulinaemic clamp and metabolic rate/substrate utilisation by open-circuit respirometry.

Results. Compared with chow-fed controls, a high-fat diet increased weight gain, an effect lessened by NO1886 [weight gain (g): chow, $37 \pm 3$, high-fat, $222 \pm 9$; high-fat + NO-1886, $109 \pm 6$, all groups differed $p<0.001]$. A similar pattern existed for fat accumula- tion [visceral fat $(\mathrm{g})$ : chow, $35.9 \pm 3.2$; high-fat, $81.9 \pm$ 6.6; high-fat + NO-1886, $52.3 \pm 4.7, p<0.01$ high-fat vs the other groups]. A high-fat diet induced wholebody insulin resistance (clamp glucose infusion rate: $4.8 \pm 1.3 \mathrm{mg} \cdot \mathrm{kg}^{-1} \cdot \mathrm{min}^{-1}$ vs $10.6 \pm 1.1$ for the chow group, $p<0.01$ ) with NO-1886 lessening this effect $(8.3 \pm 0.5, p<0.05$ vs high-fat). The 24 -h respiratory quotient was lower in the high-fat $+\mathrm{NO}-1886$ group $(0.825 \pm 0.010)$ compared with high-fat alone $(0.849 \pm 0.004, p<0.05)$. A high-fat diet increased lipoprotein and hormone-sensitive, lipase activities in epididymal fat, an effect not altered by NO-1886. In myocardium and skeletal muscle a high-fat diet lowered lipoprotein lipase activity, an effect lessened by NO-1886.

Conclusion/interpretation: Lipoprotein lipase activators could have potential benefits for the treatment of obesity by increasing fat utilisation. [Diabetologia (2000) 43: 875-880]

Keywords Hormone sensitive lipase, obesity, respiratory quotient, skeletal muscle, visceral fat.
Obesity is one of the fastest growing major diseases in developed and developing countries [1]. Modifying fat balance is a key to therapy for obesity [2]. Triglyceride is an important carrier of blood lipid and lipo-

Received: 11 January 2000 and in final revised form: 4 April 2000

Corresponding author: Dr. M. Kusunoki, The First Department of Internal Medicine, Aichi Medical University, Nagakute-cho, Aichi-gun, Aichi 480-11, Japan

Abbreviations: LPL, lipoprotein lipase; HSL, hormone-sensitive lipase; RQ, respiratory quotient; GIR, glucose infusion rate. protein lipase (LPL) strongly controls triglyceride metabolism. Lipoprotein lipase is an enzyme that hydrolyses triglycerides of triglyceride-rich lipoproteins into non-esterified fatty acids (NEFA) and glycerol. The NEFA generated as a result of these enzymatic reactions can be used for metabolic fuel in tissues such as muscle but also serve as substrate for re-esterification to triglyceride in adipose tissue. The balance of these competing effects could determine whether increased LPL activity will lead to reduced rate of weight gain (through greater disposal of ingested fats as metabolic fuel) or increased adiposity through increased rates of adipose tissue storage of triglycer- 
ide. Some reports have suggested that LPL activity in adipose tissue is high in obesity $[3,4]$.

The compound NO-1886 has previously been reported to increase post-heparin plasma LPL activity and produced a reduction in plasma triglyceride concentrations with concomitant increase of high-density lipoprotein (HDL) cholesterol concentrations [5-7]. Recently, we have shown that rats fed with fructose and treated with NO-1886 for 1 month had a lower $24 \mathrm{~h}$ mean respiratory quotient (RQ) than control rats [8]. These results suggest that NO-1886 accelerates fat oxidation and suppresses fat accumulation if given for a long period.

The aim of this study was to ascertain the effects of 10 weeks of treatment with the LPL-promoting agent NO-1886 on substrate utilisation, development of obesity and insulin action in rats eating a high-fat diet.

\section{Materials and methods}

Materials. Agent NO-1886, 4-diethoxyphosphorylmethyl- $N$ (4-bromo-2-cyanophenyl) benzamide was synthesised in the New Drug Research Laboratory of Otsuka Pharmaceutical Factory, Naruto, Tokushima, Japan. Glycerol tri [1-14 C] oleate $(2.2 \mathrm{GBq} / \mathrm{mmol})$ was obtained from Amersham, Cardiff, United Kingdom. We obtained Taq DNA polymerase and random primer from Takara Shuzo, Kyoto, Japan, RNAase inhibitor from Pharmacia LKB Biotechnology, Uppsala, Sweden and reverse transcriptase from Gibco BRL (Life Technologies), Gaithersburg, Md., USA. All other chemicals used were high-grade commercially available products.

Animal experiments. All animal experiments were approved by the local animal ethics committee of Aichi Medical University and conformed with the "Principles of laboratory animal care" (NIH publication no. 85-23, revised 1985) Male SD rats weighing $500-600 \mathrm{~g}$ at the age of 9 months were obtained from Japan SLC, Shizuoka, Japan. The animals were maintained under a 12-h light dark cycle at a constant temperature of $23 \pm 2{ }^{\circ} \mathrm{C}$. Three groups of rats were fed for 10 weeks on either: (1) a standard laboratory chow (MF chow, Oriental Yeast, Tokyo, Japan; Chow group; $6 \%$ of calories as fat and $65 \%$ as carbohydrate); (2) a high-fat diet created by mixing safflower oil into the standard laboratory chow; high-fat group; $60 \%$ of calories as fat) or; (3) the high-fat diet with NO-1886 (NO1886 group). The dosage of NO-1886 was $50 \mathrm{mg} \cdot \mathrm{kg}^{-1} \cdot \mathrm{day}^{-1}$. The animals were given free access to food and tap water. Food consumption was measured after weeks 4 and 5 on the diets and body weight was recorded weekly. The respiratory quotient of rats was measured after 10 weeks of feeding. At the end of the experimental period, the animals were killed by exsanguination under sodium pentobarbital anaesthesia. Nonfasting blood samples were collected from the posterior vena cava for lipid, glucose and insulin measurements. Plasma triglyceride and NEFA were assayed using standard kits (Wako, Osaka, Japan), glucose on a YSI 2300 glucose analyser (Yellow Springs, Ind., USA) and insulin by conventional enzyme immunoassay, with the use of the Glazyme insulin-EIA test (Wako). The visceral fat and subcutaneous fat were removed and weighed. Myocardium, soleus hindlimb muscle and epididymal adipose tissues were obtained with tongs and maintained in liquid nitrogen for measurement of hormone-sensitive lipase (HSL) and LPL activity.
Metabolic rate and respiratory quotient $(R Q)$. The metabolic rate and RQ of rats was measured at the end of the 10 -week feeding period. Individual rats were placed in a glass metabolic chamber with sufficient food and water for $24 \mathrm{~h}$. Air was drawn through the chamber at a rate of $1.5 \mathrm{l} / \mathrm{min}$. Outflow air composition was measured using an automated open-circuit respirometer (Deltatrac II, Datex, Helsinki, Finland).

Euglycaemic hyperinsulinaemic clamp studies. Insulin action was assessed in a subset of rats of each of the three groups at the end of the 10 week feeding period. Euglycaemic glucose clamps studies were done after a 12-h overnight fast. Clamps were done under anaesthetic in rats with body temperature maintained at $37^{\circ} \mathrm{C}$. For insertion of jugular and carotid cannulae rats were anesthetised with sodium pentobarbital $(50 \mathrm{mg} / \mathrm{kg}$ body weight). Extension tubings were attached to the jugular vein by an adapter so that glucose and insulin could be infused simultaneously into the jugular vein. The carotid catheter was used for blood sampling. After a 30-min basal period, a continuous infusion of human regular insulin (Novolin $\mathrm{R}$, Novo Nordisk, Copenhagen, Denmark) at a rate of 60 $\mathrm{pmol} \cdot \mathrm{kg}^{-1} \cdot \mathrm{min}^{-1}$ was given throughout the study. Blood samples were drawn at 10 -min intervals for immediate measurement of plasma glucose (YSI 2300 glucose analyser) and plasma concentration was kept constant at approximately $4.5 \mathrm{mmol} / \mathrm{l}$ by a variable infusion of $10 \%$ dextrose solution. Steady state was achieved within 60 to $100 \mathrm{~min}$ in all rats and the steady state glucose infusion rate (GIR, glucose $\left.\mathrm{mg} \cdot \mathrm{kg}^{-1} \cdot \mathrm{min}^{-1}\right)$ was obtained over the next $30 \mathrm{~min}$.

Tissue LPL activity. Myocardial and soleus heparin-triggered LPL activity was measured as reported previously [5,9]. A specimen of muscle was homogenised in $50 \mathrm{mmol} / \mathrm{l} \mathrm{NH} 4 \mathrm{Cl}$ buffer ( $\mathrm{pH} 8.5)$ and incubated with buffer containing heparin for $60 \mathrm{~min}$ at $0^{\circ} \mathrm{C}$. The suspension was then centrifuged and the supernatant used to measure LPL activity. Adipose tissue heparin-triggered LPL activity was measured as described earlier [10]. Because the high-fat content and fragility of the adipose precluded making a tissue homogenate, a specimen of adipose tissue weighing $100 \mathrm{mg}$ was minced into small pieces and placed in Krebs-Ringer bicarbonate buffer ( $\mathrm{pH}$ 7.4) in the presence of heparin for $60 \mathrm{~min}$ at $37^{\circ} \mathrm{C}$. The incubation medium was then assayed for LPL activity.

Hormone-sensitive lipase activity. Hormone-sensitive lipase activity of epididymal adipose tissue was measured by a modified Rizack method [11]. Adipose tissue weighing $1 \mathrm{~g}$ was homogenised in $4 \mathrm{ml}$ of $1 \mathrm{mmol} / 1$ EDTA- $0.25 \mathrm{~mol} / \mathrm{l}$ sucrose solution by Polytron homogeniser (Polytron, Tokyo, Japan. The supernatant was used to measure HSL activity using glycerol tri $[1-14 \mathrm{C}]$ oleate as substrate $(0.67 \mathrm{~mol} / \mathrm{l}$ phosphate buffer to maintain the enzyme's phosphorylation state; $\mathrm{pH} 6.8$ without Apo-CII).

Northern analysis for HSL A DNA fragment corresponding to position 1464-1956 on rat HSL cDNA [12] was prepared by polymerase chain reaction and used as the probe for northern analysis. Total RNA was prepared from adipose tissue of rats by the acid guanidium-thiocyanate method [13]. From the total RNA $10 \mu \mathrm{g}$ was transferred to a nylon membrane. The membrane was hybridised in Rapid hybridisation buffer (Amersham International) with probes at $65^{\circ} \mathrm{C}$ for $2 \mathrm{~h}$.

Statistical analysis. Comparisons were by ANOVA followed by Newmann-Keuls post-hoc examination of intergroup differences. A $p$ value of 0.05 or less was considered statistically significant. 


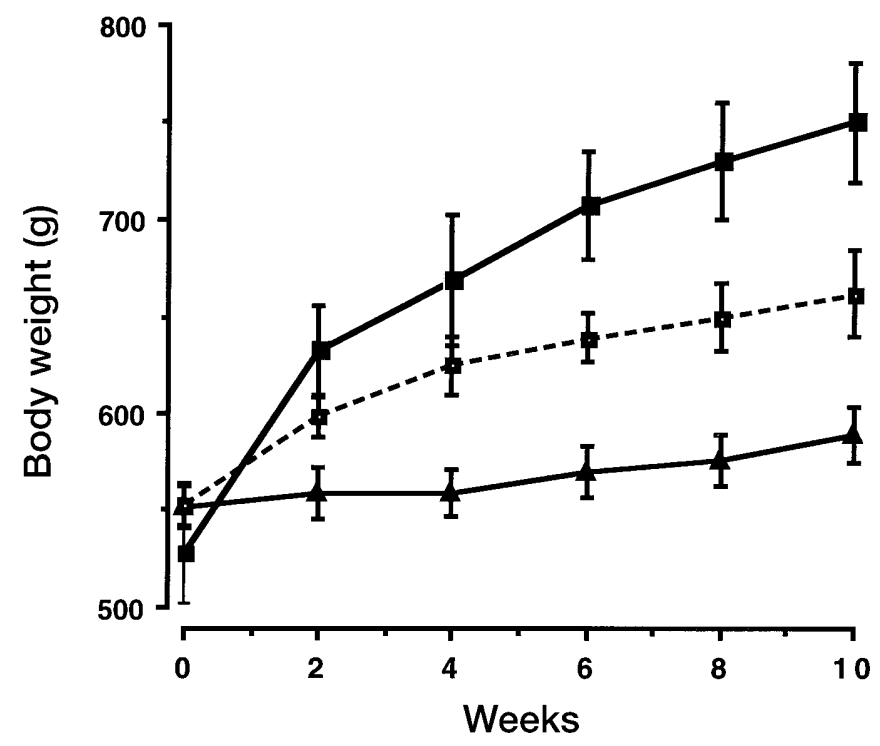

Fig. 1. Effects of chow or a high-fat diet with and without NO$1886\left(50 \mathrm{mg} \cdot \mathrm{kg}^{-1} \cdot \mathrm{day}^{-1}\right)$ for 10 weeks on body weight gain. Body weight was significantly different between all three groups by 6 weeks of feeding/drug treatment and remained so for the duration of treatment. - $\mathbf{-}$, high fat; - - - $\mathbf{\square}--$, highfat + NO-1886; $-\mathbf{\Delta}-$, chow

\section{Results}

Effects of NO-1886 on body weight gain, food consumption and blood variables. The body weight of the group of rats fed a high-fat diet was significantly increased compared with the chow group by the 2 nd week of feeding and remained so for the duration (Fig.1). Addition of NO-1886 to the high-fat diet reduced the weight gain such that the NO-1886 group had a statistically significantly lower body weight from week 6 to the end of the experiment. The body weight of the NO-1886 group was, however, significantly higher than that of the chow group. Food intake was about $15 \%$ higher in the high-fat groups than the Chow group. No overall difference in food intake could be detected between the high-fat and highfat + NO-1886 groups (mean of weeks 4, 5 and 6: highfat: $100.9 \pm 7.2$; high-fat + NO-1886: $97.8 \pm 6.0$ vs $85.3 \pm 5.4 \mathrm{kcal} /$ day in the chow group). A high-fat diet significantly increased triglyceride, NEFA, glucose and insulin concentrations. Treatment with NO-1886
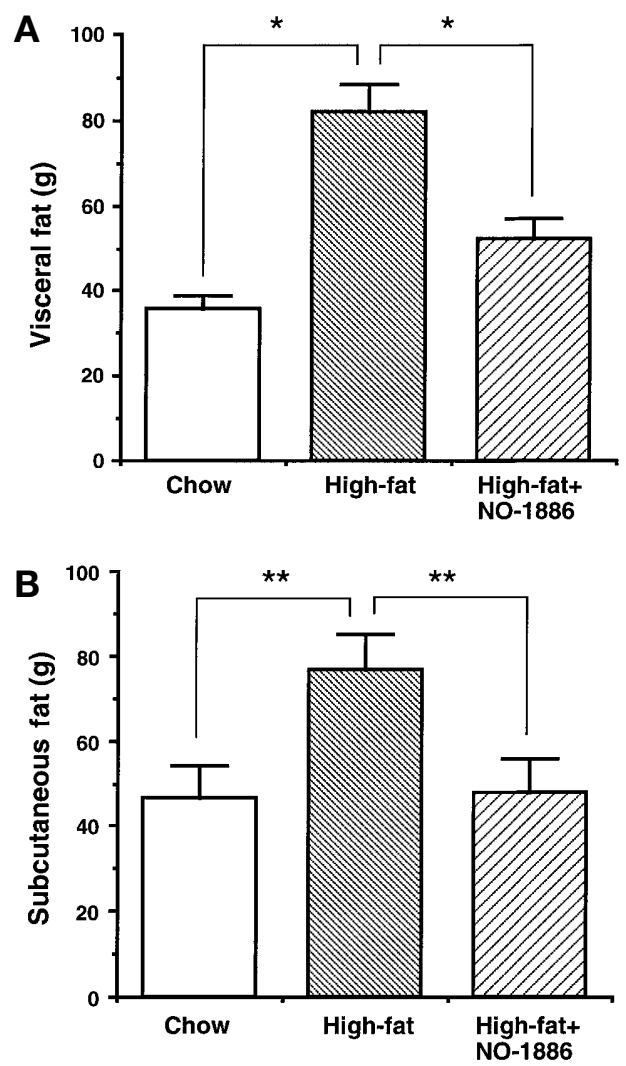

Fig. 2A, B. Effects of chow or a high-fat diet with and without NO-1886 $\left(50 \mathrm{mg} \cdot \mathrm{kg}^{-1} \cdot \mathrm{day}^{-1}\right)$ for 10 weeks on visceral fat $(\mathbf{A})$ and subcutaneous fat $(\mathbf{B})$ accumulation. ${ }^{*} p<0.01,{ }^{* *} p<0.05$

lowered blood lipid concentrations to below those in the chow group, restored insulin concentrations to normal but did not significantly lower glucose (Table 1).

Effects of NO-1886 on visceral fat and subcutaneous fat weight. The high-fat group had a 2.3-fold increased visceral and subcutaneous fat weight compared with the chow group (Fig. 2). Treatment with NO-1886 significantly suppressed the increase in accumulation of visceral fat and subcutaneous fat.

Effects of NO-1886 on metabolic rate and RQ. Addition of NO-1886 to the high-fat diet resulted in an RQ significantly lower than that observed for the high-fat group alone (Fig.3). Energy expenditure was $113.4 \pm 1.6 \mathrm{kcal} \cdot 24 \mathrm{~h}^{-1} \cdot \mathrm{kg}$ body weight ${ }^{-1}$ in the

Table 1. Non-fasting plasma lipids, glucose and insulin concentrations in control, high-fat-diet and NO-1886 treated high-fat-diet rats

\begin{tabular}{llllcc}
\hline & $n$ & $\begin{array}{l}\text { Triglycerides } \\
(\mathrm{mmol} / \mathrm{l})\end{array}$ & $\begin{array}{l}\text { NEFA } \\
(\mathrm{g} / \mathrm{l})\end{array}$ & $\begin{array}{l}\text { Glucose } \\
(\mathrm{mmol} / \mathrm{l})\end{array}$ & $\begin{array}{l}\text { Insulin } \\
(\mathrm{pmol} / \mathrm{l})\end{array}$ \\
\hline Chow & $(9)$ & $1.53 \pm 0.04^{\mathrm{a}}$ & $0.145 \pm 0.003$ & $9.16 \pm 0.15^{\mathrm{b}}$ & $345 \pm 28^{\mathrm{b}}$ \\
High-fat & $(6)$ & $2.02 \pm 0.16$ & $0.162 \pm 0.013$ & $10.55 \pm 0.29$ & $606 \pm 73$ \\
High-fat + NO-1886 & $(6)$ & $1.04 \pm 0.06^{\mathrm{b}, \mathrm{c}}$ & $0.116 \pm 0.005^{\mathrm{b}, \mathrm{c}}$ & $9.77 \pm 0.13$ & $384 \pm 54^{\mathrm{a}}$ \\
\hline
\end{tabular}

Data are expressed as means \pm SEM. Significantly different from the high-fat-diet group: ${ }^{\mathrm{a}} p<0.05,{ }^{\mathrm{b}} p<0.01$. Significantly different from the chow group, ${ }^{\mathrm{c}} p<0.01$ 


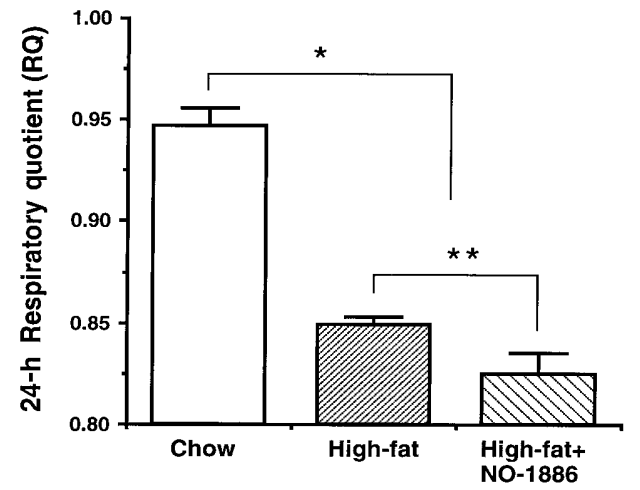

Fig.3. Effects of chow or a high-fat diet with and without NO$1886\left(50 \mathrm{mg} \cdot \mathrm{kg}^{-1} \cdot \mathrm{day}^{-1}\right)$ for 10 weeks on 24 -h respiratory quotient (RQ) determined at the end of the 10 week treatment. Respiratory quotient was measured with free access to usual food/drug and water. ${ }^{*} p<0.001,{ }^{* *} p<0.05$

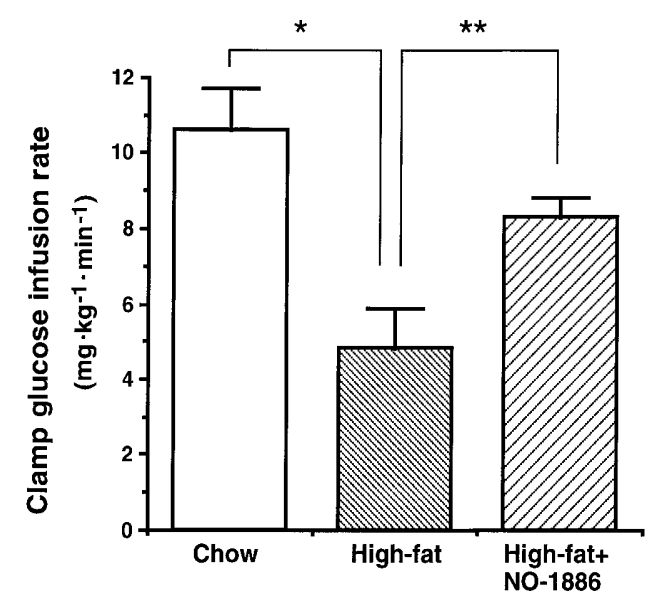

Fig.4. Effects of chow or a high-fat diet with and without NO$1886\left(50 \mathrm{mg} \cdot \mathrm{kg}^{-1} \cdot \mathrm{day}^{-1}\right)$ for 10 weeks on insulin action as assessed by the glucose infusion rate to maintain euglycaemia in the face of an insulin increase by continuous infusion of insulin at a rate of $60 \mathrm{pmol} \cdot \mathrm{kg}^{-1} \cdot \mathrm{min}^{-1}$. Steady-state whole-blood glucose concentrations did not differ significantly between groups and were: chow group: $4.8 \pm 0.3 \mathrm{mmol} / 1$, high-fat $5.6 \pm 0.4$, high-fat + NO-1886 $4.9 \pm 0.2 .^{*} p<0.01,{ }^{* *} p<0.05$

chow group, $101.3 \pm 3.1$ in the high-fat group and $112.2 \pm 2.0$ in the high-fat + NO-1886 group ( $p<0.05$, high-fat vs the other two groups).

Effects of NO-1886 on insulin action Fasting insulin and glucose concentrations did not differ between groups and there were no differences during the plateau phase of the euglycaemic hyperinsulinaemic clamp (data not shown). A high-fat diet led to a significant insulin resistance which was reduced by the addition of NO-1886 (Fig. 4).

Effects of NO-1886 on tissue LPL activity. Skeletal muscle LPL activity was reduced by a high-fat diet, with a trend to reduction $(p<0.10)$ by NO-1886 (Fig. 5). Myocardium LPL activity was not altered by a high-fat diet but NO-1886 statistically significantly increased myocardium LPL activity. Epididymal adipose tissue LPL activity of rats eating a high-fat diet increased 4.1-fold compared with the chow group. Treatment with NO-1886 had no effect on this adipose tissue increase of LPL activity caused by a high-fat diet when expressed per g of tissue (Fig.5). Given the reduced visceral adipose tissue mass and assuming that the LPL results in epididymal adipose can be generalised to the rest of the visceral fat, LPL activity overall in visceral adipose tissue is, however significantly reduced by NO-1886 (Fig. 5).

Effects of NO-1886 on the expression HSL and HSL activity. High-fat diet did not alter the HSL mRNA: cyclophillin mRNA ratio in epididymal adipose tissues (Table 2). The activity of HSL was, however, increased by a high-fat diet. The further $24 \%$ increase of HSL activity with high-fat + NO-1886 did not reach statistical significance.

\section{Discussion}

As has been persuasively argued, long-term imbalance between intake and expenditure of fat is a central factor in the aetiology of obesity [2]. Hence the distribution of lipid between adipose tissue (largely storage) and muscle (largely oxidation) is critical. A role for tissue-specific regulation of LPL in treatment of obesity was postulated some time ago [14]. Rats that are fed a high-fat diet are a useful model of the metabolic syndrome being among other things, insulin resistant and obese. In this study we have shown that NO-1886 in a high-fat diet tends to increase muscle LPL, reduce body weight and fat accumulation and improve insulin action, all consistent with the increase in fat oxidation (lowered RQ) observed. These results are consistent with the recent observation that diet-induced obesity in mice can be prevented by creating transgenics overexpressing a skeletal muscle-specific human $L P L$ gene [15]. Taken together these results suggest that tissue-specific LPL activators have potential in therapy for obesity and related disorders.

A high percentage of fat in the diet is considered an important factor in the development of obesity, leading to insulin resistance and accumulation of body fat even in the absence of increased caloric intake [16]. Our results show that a high-fat diet differentially affects LPL activity in muscle and adipose tissue, reducing the former and greatly increasing the latter. This pattern is consistent with the shift towards fat storage. An increase in muscle LPL activity with NO-1886 treatment would lead to greater availability of intramuscular fatty acid. Theoretically this could have led to either an increased storage of triglyceride 

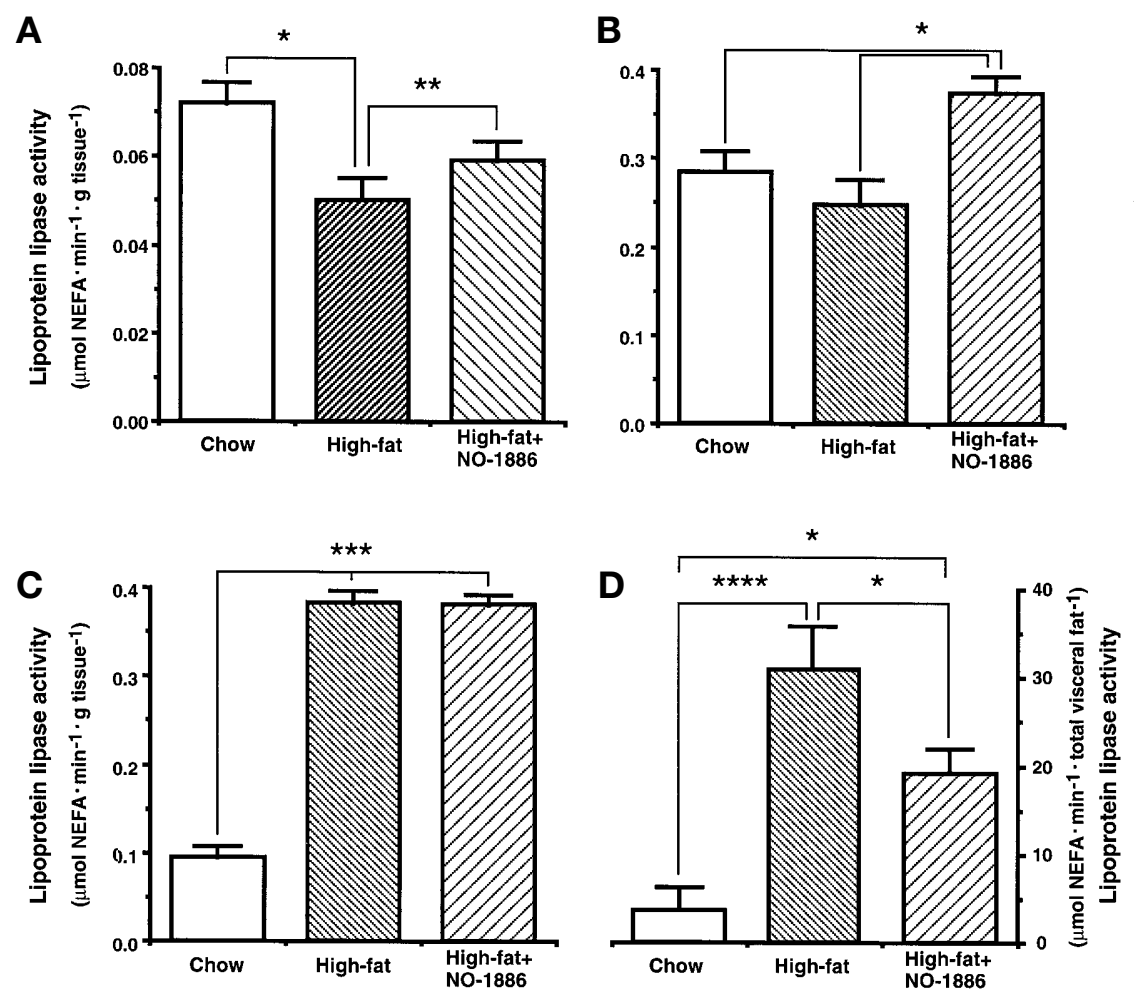

Fig. 5. Effects of chow or a high-fat diet with and without NO$1886\left(50 \mathrm{mg} \cdot \mathrm{kg}^{-1} \cdot \mathrm{day}^{-1}\right)$ for 10 weeks on soleus skeletal muscle (A), heart muscle (myocardium) (B) and epididymal white adipose tissue LPL activity $(\mathbf{C})$. D shows visceral adipose tissue total heparin-releaseable LPL activity assuming that the LPL activity in epididymal fat is representative of the visceral fat in general. ${ }^{*} p<0.05,{ }^{* *} p<0.10,{ }^{* * * *} p<0.001,{ }^{* * * * *} p<0.01$

in muscle or enhanced lipid utilisation. The storage of lipid in skeletal muscle has been shown to be related to insulin resistance in rats and humans [16-18]. In our study NO-1886 led, however, to an increase in fat oxidation (indexed by lowered RQ) and an improvement in insulin action consistent with the lipid available in muscle being oxidised rather than increasingly stored. This is important given the recent report that in obesity skeletal muscle metabolism favours fat esterification over oxidation [19] and is consistent with our previous report that NO-1886 statistically significantly decreased RQ and plasma triglyceride concentrations in fructose-fed rats [8]. This latter decrease is not accompanied in most tissues by in-

creased tissue accumulation of triglyceride. On a per $\mathrm{kg}$ of body weight basis, a fat diet also reduced energy expenditure, an effect reduced by NO-1886. This result must, however, be treated with some caution as the measurement of energy expenditure was made at the end of the treatment period when there were likely to be substantial differences in body composition between the groups.

Net adipocyte fat storage is a balance between lipogenesis and lipolysis. In transgenic mice ubiquitous overexpression of the human LPL has been shown not to result in an increase in fat deposition, the balance apparently being maintained as a result of increased hormone-sensitive lipase (HSL) [20]. In this study, HSL activity in adipose tissue was increased by a high-fat diet but mRNA was not altered. This suggests that a high-fat diet could have increased the activated form of HSL. The net effect in rats fed a high fat diet was still an increased fat accumulation with raised LPL activity which was not fully balanced by the increased HSL. Treatment with NO-1886 increased epididymal adipose tissue HSL by $24 \%$ ( $p<0.10$ vs highfat). Although only a non-significant trend, it could

Table 2. Effects of NO-1886 on expression of HSL mRNA and HSL activity in epididymal adipose tissue

\begin{tabular}{|c|c|c|c|}
\hline & $n$ & $\begin{array}{l}\text { HSL mRNA activity } \\
\text { HSL/Cyclophillin }\end{array}$ & 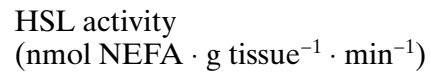 \\
\hline Chow & $(5)$ & $0.572 \pm 0.053$ & $6.62 \pm 0.71^{\mathrm{a}}$ \\
\hline High-fat & (5) & $0.498 \pm 0.030$ & $10.47 \pm 0.95$ \\
\hline
\end{tabular}

Data are expressed as means \pm SEM. Significantly different from the other two groups

${ }^{\mathrm{a}} p<0.01$ 
have contributed, along with the effects in muscle, to the overall improvement in fat balance seen in that group. Note, the type of fat could also have a role as it has been reported that using saturated fats in a highfat diet resulted in the greatest obesity and polyunsaturated fats a significantly lower gain in weight [20]. Consistent with this observation, LPL activity in heart and skeletal muscle was increased in the polyunsaturated group compared with rats eating a more saturated-fat diet [21]. Equally, there is evidence that a more saturated-fat diet decreases adrenergic receptor binding [22] and a role for catecholamines in tissue-specific regulation of lipoprotein lipase has been shown in humans [23]. In our study we used safflower oil (mainly $\mathrm{n}-6$ polyunsaturated fatty acids) which we have consistently been shown produces insulin resistance [16]. Our effects might, however, have been larger if a more saturated-fat diet had been used.

An inverse relation between RQ and skeletal muscle LPL activity has also been shown in humans [24] and there is evidence that high RQ (low fat utilisation) is predictive of subsequent weight gain [25]. In addition, in women who have been obese, there is substantial impairment in the ability to increase fat oxidation in the face of increased dietary fat load [26]. Taken together with the current findings, these results focus on muscle LPL activity and on the possibility of increased fat utilisation as a therapeutic approach to the problem of obesity.

The lipoprotein lipase-promoting agent NO-1886 increased muscle LPL activity without affecting (or perhaps even reducing on a total tissue basis) adipose tissue LPL activity and lowered the RQ in rats fed a high-fat diet. These combined effects might have led to the suppression in the accumulation of visceral and subcutaneous fat and reduction in the insulin resistance induced by a high-fat diet. The authors acknowledge that increased LPL activity might only be one of the actions of NO-1886 and we have not directly shown that it is this action that results in the beneficial effects on adiposity and insulin action. This class of compound could, however, have potential benefit for treatment of obesity and related disorders.

\section{References}

1. Popkin BM, Doak CM (1998) The obesity epidemic is a worldwide phenomenon. Nutr Rev 56: 106-114

2. Flatt JP (1995) McCollum Award Lecture, 1995 Diet, lifestyle, and weight maintenance. Am J Clin Nutr 62: 820-836

3. Kern PA, Ong JM, Saffari B, Carty J (1990) The effects of weight loss on the activity and expression of adipose tissue lipoprotein lipase in very obese humans. N Engl J Med 322: 1053-1059

4. Sadur CN, Yost TJ, Eckel RH (1984) Insulin responsiveness of adipose tissue lipoprotein lipase is delayed but preserved in obesity. J Clin Endcrinol Metab 59: 1176-1178

5. Tsutsumi K, Inoue Y, Shima A, Iwasaki K, Kawamura M, Murase T (1993) The novel compound NO-1886 increases lipoprotein lipase activity with resulting elevation of high density lipoprotein cholesterol, and long-term administration inhibits atherogenesis in the coronary arteries of rats with experimental atherosclerosis. J Clin Invest 92: 411-417

6. Tsutsumi K, Inoue Y, Shima A, Murase T (1995) Correction of hypertriglyceridemia with low high-density lipoprotein cholesterol by the novel compound NO-1886, a lipoprotein lipase-promoting agent, in STZ-induced diabetic rats. Diabetes 44: 414-417

7. Tsutsumi K, Inoue Y, Hagi A, Murase T (1997) The novel compound NO-1886 elevates plasma high-density lipoprotein cholesterol levels in hamsters and rabbits by increasing lipoprotein lipase without any effect on cholesteryl ester transfer protein activity. Metabolism 46: 257-260

8. Hara T, Cameron-Smith D, Cooney GJ, Kusunoki M, Tsutsumi K, Storlien LH (1998) The actions of a novel lipoprotein lipase activator, NO-1886, in hypertriglyceridemic fructose fed rats. Metabolism 47: $149-153$

9. Murase T, Uchimura H (1980) A selective decline of post-heparin plasma hepatic triglyceride lipase in hypothyroid rats. Metabolism 29: 797-801

10. Murase T, Yamada N, Matsuzaki F (1981) The in vitro effect of growth hormone on adipose tissue lipoprotein lipase in rats. Life Sci 28: 199-201

11. Rizack MA (1961) An epinephrine-sensitive lipolytic activity in adipose tissue. J Biol Chem 236: 657-662

12. Holm C, Kirchgessner TG, Svenson KL, Lusis AJ, Belfrage P, Schotz C (1988) Nucleotide sequence of rat adipose hormone sensitive lipase cDNA. Nucleic Acid Res 16: 9879

13. Sambrook J, Fritsch EF, Maniatis T (1989) Extraction, purification and analysis of messenger RNA from eukaryotic cells. In Molecular Cloning, 2nd edn. Cold Springs Harbor Laboratory, Cold Springs Harbor, New York, pp 1-87

14. Eckel RH (1989) Lipoprotein lipase. A multifunctional enzyme relevant to common metabolic diseases. N Engl J Med 320: 1060-1068

15. Jensen DR, Schlaepfer IR, Morin CL et al. (1997) Prevention of diet-induced obesity in transgenic mice overexpressing skeletal muscle lipoprotein lipase. Am J Physiol 273: R683-R689

16. Storlien LH, Jenkins AB, Chisholm DJ, Pascoe WS, Khouri S, Kraegen EW (1991) Influence of dietary fat composition on development of insulin resistance in rats. Relationship to muscle triglyceride and $\omega-3$ fatty acids in muscle phospholipids. Diabetes 40 : 280-289

17. Phillips DI, Caddy S, Ilic V et al. (1996) Intramuscular triglyceride and muscle insulin senstivity:evidence for a relationship in nondiabetic subjects. Metabolism 45: 947-50, 1996

18. Pan DA, Lillioja S, Kriketos AD et al. (1997) Skeletal muscle triglyceride levels are inversely related to insulin action. Diabetes 46: 983-988

19. Simoneau JA, Veerkamp JH, Turcotte LP, Kelley DE (1999) Markers of capacity to utilize fatty acids in human skeletal muscle:relation to insulin resistance and obesity and effects of weight loss. FASEB J 13: 2051-2060

20. Shimada M, Ishibashi S, Yamamoto K et al. (1995) Overexpression of human lipoprotein lipase increases hormone-sensitive lipase activity in adipose tissue of mice. Biochem Biophys Res Commun 211: 761-766

21. Shimomura Y, Tamura T, Suzuki M (1990) Less body fat accumulation in rats fed a safflower oil diet than in rats fed a beef tallow diet. J Nutr 120: 1291-1296

22. Matsuo T, Suzuki M (1997) Brain beta-adrenergic receptor binding in rats with obesity induced by a beef tallow diet. Metabolism 46: $18-22$

23. Eckel RH, Jensen DR, Schlaepfer IR, Yost TJ (1996) Tissue-specific regulation of lipoprotein lipase by isoproterenol in normalweight humans. Am J Physiol 271: R1280-R1286

24. Ferraro RT, Eckel RH, Larson DE et al. (1993) Relationship between skeletal muscle lipoprotein lipase activity and 24-h macronutrient oxidation. J Clin Invest 92: 441-445

25. Zurlo F, Ravussin E (1992) A low rate of fat utilization as a predictor of weight gain. In: Belfiore F, Jeanrenaud B, Papalia D (eds) Obesity: Basic Concepts and Clinical Aspects. Karger, Basel, pp $50-60$

26. Astrup A, Buemann B, Christensen NJ, Toubro S (1994) Failure to increase lipid oxidation in response to increasing dietary fat content in formely obese women. Am J Physiol 266: E592-E599 